\title{
DIVISION III WORKING GROUP on PLANETARY SYSTEM NOMENCLATURE
}

PRESIDENT
VICE-PRESIDENT
PAST PRESIDENT
MEMBERS

PRESIDENT PAST PRESIDENT MEMBERS

\author{
Rita Schulz \\ K. Aksnes, J. Blue, E. Bowell \\ G. A. Burba, G. Consolmagno, R.Courtin \\ R. Lopes, M. Ya. Marov, B. G. Marsden \\ M. S. Robinson, V. V. Shevchenko, B. A. Smith
}

\section{PROCEEDINGS BUSINESS SESSIONS, 7 August 2009}

\section{Introduction}

The meeting was attended by 5 members of the WG (E. Bowell, G. Consolmagno, R. Courtain, R. Lopez, R. Schulz) one Task Group member (J. Watanabe), and several guests from the CSBN and CBAT. It was decided at the beginning of the meeting that the attending members of the WGPSN would discuss matters, provide their opinion or vote, and then ask the other 8 formal members to do the same via email. As a consequence the following discussed items have been agreed by majority vote of the WG members.

\section{Discussion Items}

In the first part of the meeting four specific items were addressed which needed discussion and agreement by the WG.

1) An information email shall be sent to CBAT every time a satellite has been officially named.

2) Categories of proper names shall be approved by the WG before being implemented by the TG.

3) If biographical information is only available in a language the WGPSN members cannot understand, a translation of this information into English should be made available, whereby it has to be ensured that this translation comes from a bona fide source. (The English language was chosen for practical reasons, because all members of the WG would speak it.) The respective TG chair is required to provide an English translation.

4) The need for relaxing rules about internet sources was discussed. The WG was of the opinion that it is not yet time for trying to put up a general rule on the use of internet sources. It was however noted that it should be allowed to use internet sources if no other sources are available and if the internet source is a bona fide source, of which the likelihood of staying available is not smaller that for non-internet sources (e.g. the Britannica). This issue should be discussed for the time being on a case by case basis.

If an internet page is used that page will be saved as a pdf file, linked to the sources page ("http://planetarynames.wr.usgs.gov/jsp/append4.jsp"), and stored at the USGS (in case the site becomes unavailable in the future).

\section{Closing remarks}

As the integration of the WGPSN from the Executive Committee into Division III has resulted in communication problems that affected the work, authority, and reputation of the WG, options for solving this problem were discussed. It was confirmed that the D-III president has the 
obligation to forward any information concerning the WGPSN to the WG chair. After discussion the WGPSN agrees that moving the WGPSN back to reporting directly to the EC provides the only effective solution to the communication problem. The IAU President has therefore been contacted and requested to suggest this topic as an agenda item at the next EC meeting.

Rita Schulz

President of the Working Group 